\title{
Going digital: case study of an Italian insurance company
}

\section{Galena Pisoni}

Galena Pisoni is based at the Department of Information Engineering and Computer Science, University of Trento, Trento, Italy.
(C) Galena Pisoni. Published by Emerald Publishing Limited. This article is published under the Creative Commons Attribution (CC BY 4.0) licence. Anyone may reproduce, distribute, translate and create derivative works of this article (for both commercial and non-commercial purposes), subject to full attribution to the original publication and authors. The full terms of this licence maybe seen at http:// creativecommons.org/licences/ by/4.0/legalcode

The author would like to thank the company host Assinord Verona S.R.L. and all the employees for their time and effort dedicated to this project.
0 ince the first insurance contract, dating from over 600 years ago, the basic model of how insurance companies work has remained unchanged. Companies compensate clients financially against loss or damage from a specified event. Customers pay premiums to obtain such coverage. The long history of insurance has proven that the model works. People and businesses buy insurance products and studies show that consumers have a high level of confidence in the industry.

While insurance companies continue doing business the same way they have for years, they have failed to innovate. This failure to improve is most glaring with the customer experience. For example, many customers have difficulty understanding the differences between insurance policies and complicated insurance contracts. Many do not understand the conditions of the contracts and they are not confident the insurance product offered will satisfy their needs completely.

Customer expectations have changed. In the past, when buying goods or services, customers had few possibilities to compare prices between local agents or dealers. With the emergence of the internet, this has changed and readily accessible information allows for 24/7 active comparisons and searches for the best price via different channels.

Because of digital transformation, insurance consumers increasingly want to interact with companies anytime and anywhere. Therefore, companies constantly search for new ways to engage consumers digitally and where they want to be engaged. Companies are now expected to engage via channels such as text, chat, voice assistants, websites and mobile devices for customer acquisition and service. If a company does not offer a positive digital experience, many customers, particularly younger people, will move to industry competitors that offer better customer experiences digitally or they may turn to adjacent industries that offer the service as an "add on."

Most insurance companies are left with systems, processes and practices that would be still recognizable by those in the industry in the 1980s. Though the insurance sector has stagnated, changes across other industries have been groundbreaking (invention of smartphones, social media, YouTube, Google and Amazon). Changes brought by digitalization of other industries exert even more pressure to the insurance industry.

A new era also brings new risks. For instance, organizations are increasingly concerned about their cyber risk exposure. As a result, companies have increasingly turned to the insurance industry with a need for cyber risk insurance products to better manage cyber threats and any resulting legal liability from data breaches. These new 
risks are opening the doors for insurance companies to provide new products and services, but the industry is immature and takes considerable resources to develop products and services in this new market. New technologies such as big data, cloud computing and social media increase the risks resulting from cybercrimes and cyber risks are now one of the top concerns of business leaders. Every organization is vulnerable to potential losses resulting from electronic data theft. Organizations want to protect themselves and their reputations from cyber risks as well as the data and records of their customers. For this, they turn to insurance companies, which in turn may not be prepared to help a company understand its cyber security risk profile.

To help with the challenges associated with technology disruption, insurance companies rely on a wave of freshly created companies called InsurTechs. The term "Insures" refers to an ecosystem of companies that operate in the insurance technology domain, usually focusing on a specific line of business, area in the value chain or client segment. InsurTechs are created as digital native companies. These digital startups allow insurance companies to improve and enhance their digital capabilities; helping them change the established way they work and interact with customers. InsurTechs aim to generate value for customers, for insurance companies or both. While the key elements of the insurance models remain the same, the industry continues to evolve. According to the literature (Reindeer et al., 2019), there are three approaches that characterize how InsurTechs work. They may help clients to:

1. leverage the most advanced technologies, as the most innovative solutions are at the core of the company;

2. focus on improving the experience to foster a user-centric approach, for instance, some focus on improving the purchasing stage, the underwriting process or streamlining claims management; and

3. develop an agile culture and approach, along with leveraging analytics to make faster business decisions.

In this paper, we analyze what small- and medium-sized insurance companies can do to leverage new technology and describe digital transformation in an Italian company that used this approach.

\section{The case study company}

Assinord Verona S.R.L. offers insurance products in five different lines of business (all types of insurance products) and functioning relies on 15 people in the company and a number of collaborators from all over Italy that contribute to the growth of the company. Now, the company has more than 10,000 clients across Italy.

The aim of this research was to identify which digital transformation trends the company should adopt to better serve its business goals as established by the founding partners. Together with the founders, the author investigated the company

\section{While insurance companies continue doing business the same way they have for years, they have failed to innovate. This failure to improve is most glaring with the customer experience.}




\section{Together with the founders, the author investigated the company value chain and identified where it could benefit from new technologies available on the market.}

value chain and identified where it could benefit from new technologies available in the market. We identified a few use cases to focus on and evaluated a "build" or "buy" approach for the technology. We also looked at how to best integrate these new technologies into the everyday functioning of the company. The process included the following steps:

- The study of the adoption strategy of innovative digital insurance solutions to improve everyday operations of the company.

- Understanding the needs of the company and the customers with one-on-one sessions with team members and the development of first prototype for a platform to better connect the company with the customers.

- The study of different cyber risk policies to enrich the product portfolio and company offering.

We explored the company offers and the established company processes to understand how to implement effective digital transformation. We studied the differences in complex insurance offers for existing clients and the author talked with the owners to understand how to make the whole process smoother.

The paper is organized as follows: in Section 2, we present the analysis of the different strategies to approach innovation and the one chosen by the company; in Section 3, we present the platform for connecting the company with the clients; and in Section 4, we present the analysis of cyber risks and the kind of insurance policies the company enriched the portfolio with to offer more up-to-date products. We conclude the paper with Section 5, in which we present the takeaways from the process and recommendations for potential next steps.

\section{Strategy for adoption of new insurance technologies}

Based on the literature, we researched how other companies of similar size have approached the digital transformation phenomenon and which approach best fits this company. We summarize the different strategies used by companies in the past: internal innovation, buy from startups, partner with startups and invest in startups. A brief summary of the different methods and the reaction to these by the company is discussed.

\section{Internal innovation}

One strategy that companies have been using to embrace digital trends is to foster innovation and the birth of new ideas internally. Different tools and methods for internal innovation have been described in the literature (Wilson, 2017; O'Brien, 2004; Kohli and Melville, 2019). We present a summary of the possible tools to use in Figure 1. With internal innovation, the idea is to encourage employees to generate ideas from their everyday experience and rely on simple methods such as researching current trends, applying customer intelligence, identifying customer needs, applying design thinking and user-driven innovation to implement process improvements and redesign business 


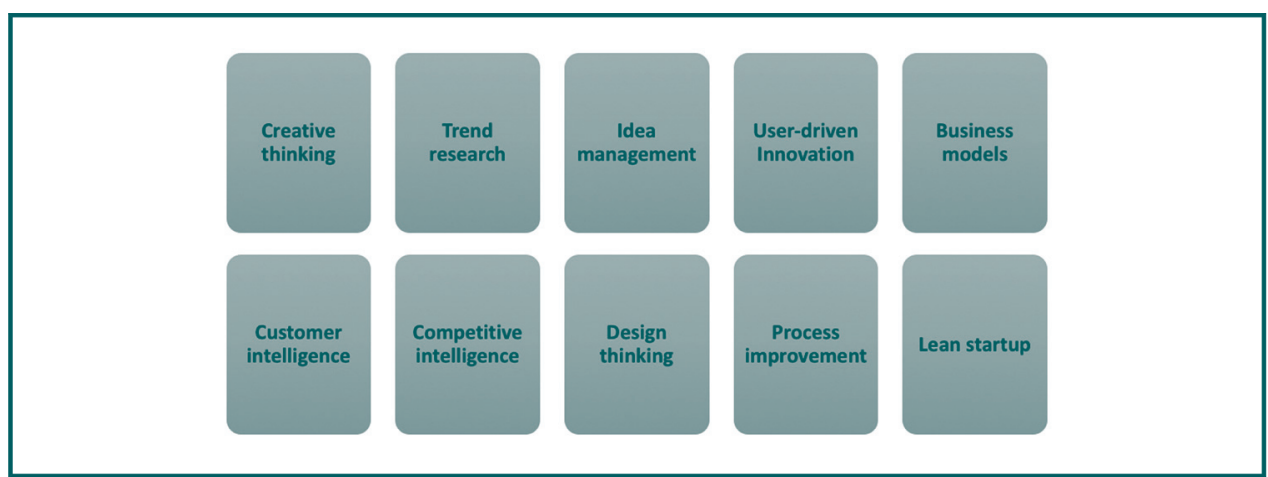

strategies. Key to this process is using brainstorming techniques to come up with innovative ideas.

The company's ability to implement the ideas is limited and that is why ideas generated internally are usually implemented by dedicated teams.

\section{Buy from startups}

Other companies partner with tech startups by purchasing their services, licensing their solutions or co-developing solutions. Companies usually partner with highly specialized startups on new technologies that insurance companies can purchase to improve operations. One such example is Cognotekt, which provides software as a service for insurers to automate claims. Another example is Insurify, a personal insurance company that compares car insurance.

\section{Partner with startups}

Another strategy involves partnering with other companies to offer services to customers by bundling offers between two companies or by providing customers new "white brand" products. New technologies require special knowledge and expertise that insurance companies do not usually have. Existing insurers can partner with technology companies to innovate along different parts of the customer value chain.

\section{Invest in startups}

This strategy is most common for big incumbents but is occasionally used by smaller companies. This approach involves investing in a startup that may rely upon one incumbent for funding. The majority of the world's largest insurers (AXA, Allianz, AIG, MetLife and Generali) have established their own in-house venture capital (VC) funds and committed investment in startups. These insurers select the areas where they want to innovate, and then look for startups in the field. In 2019, more than 140 traditional and corporate VC firms invested in an InsurTech startup.

\section{What did the company decide?}

Existing literature suggests the principles a company should follow when deciding on InsurTechs and the collaboration models for implementing such collaboration (buy, collaborate or invest) (Nicoletti, 2017): 
- The objectives when partnering with an InsurTech startup should be clearly aligned with the expected impact, which should be incremental, adjacent or transformative.

- Business objectives should determine the model of cooperation and help to prioritize solutions and types of relationships to have with the InsurTech startups.

- When choosing the companies to collaborate with, the expected impact on the company operations should be quite clear.

The different options were presented to the case study company and the decision was to do both: to try internal innovation (and in the following section, we show some examples of this approach) and to look for startups to buy products from or partner with in cases where there are mutual benefits. For the latter, we decided to rely on Plug and Play in Munich.

Partnership with Plug and Play in Munich: Plug and Play accelerates and invests in startups. It runs over 28 stage agnostic programs a year and invests in over 260 companies. Plug and Play matches startups and corporations worldwide. Our company chose to get in touch with the headquarters in Munich to start collaboration. Plug and Play supports three main lines of program: product innovation (startups working on digital transformation, improving user experience and risk assessments), new sources of risk (startups working on cyber security and other modern concerns) and disruptive ideas (startups working on industry changing business models such as the shared economy that are transforming current markets). The company decided to continue looking into startups coming from the production innovation track. In sequential meetings, different solutions will be presented to the business owners and will be made available for future analysis.

\section{Platform for connecting the company with the clients}

In this section, we show the results from pursuing internal innovation efforts to come up with a platform for connecting the company with its clients.

We started with underlining the actors involved in the system (customers and people inside the company) by using design thinking (Brown and Wyatt, 2010; Kumar, 2009) and creative facilitation (Van Boeijen et al., 2014) as methods. The author performed one-to-one interviews with customers of the company to understand what kind of technology can better serve their needs in terms of insurance and can bring a better understanding of complicated insurance terms and contracts. The author performed 15 interviews (each lasting $1 \mathrm{~h}$ ) with loyal clients the company selected. The questions were intended to help us understand how customers make buying insurance policy decisions. It also mapped the user experience from the time the individual started thinking about buying insurance all the way through the actual purchase of the insurance policy. In our search for the best ideas, we also involved employees. The author had three brainstorming sessions (each lasting $1 \mathrm{~h}$ ) in which all the employees participated. In

The users were curious to find out about the recommended amount that was proposed to them and were very interested in reading the detailed descriptions on why the suggested amount was suited for their particular case. 


\section{With these products, the company enriched its portfolio of insurance products covering cyber products.}

the brainstorming sessions, the employees were asked to reflect on the needs and situations in which the customers usually buy products (the customer interview data were given as input for each session) and they were asked to develop ideas for design concepts. These concepts were used later to develop a prototype.

From the interviews with the customers and employee brainstorming sessions, it became clear that life insurance policies presented a clear opportunity to simplify the user experience. We pursued this further by working on a prototype. After all the data was gathered and analyzed, we developed a prototype that would advise the customer about the ideal amount of life insurance coverage they should purchase. The prototype was based on demographic data entered by the consumer (age, income, partner's income and children). This data made it possible to better understand the consumer's life situation to present them with a recommended amount of life insurance. With this information, the yearly premium could be calculated and presented to the customer for the suggested amount of life insurance.

The prototype also helped with understanding the operations of the company. Usually only one employee in the company performs these tasks, recommending the amount of life insurance a person should have. This employee makes recommendations based on his own experience. With this prototype, the idea is to create a tool that optimizes the process to recommend and quote life insurance, by enabling all employees to do life insurance quotes, eliminating the need to rely on or wait for a single employee with such knowledge. It also allows better productivity by making it faster to do estimates.

When we decided to move in the direction of developing a prototype, we analyzed the idea from several aspects and set out to answer the following questions:

Q1. Does the idea enhance the existing product offering?

Q2. Is the solution compliant with regulatory requirements or are they unknown or undefinedat the moment?

Q3. Is the idea something the customer wants and needs?

Q4. Is the idea commercially viable? Does it bring potential commercial benefits for the company and is it feasible to implement?

This process has been adapted from different approaches for service design presented in Kimbell (2014). The idea seemed to satisfy all the above-mentioned aspects. After several iterations of the design, we came up with the prototype shown in Figures 2-4.

We tested the prototype with several customers and several employees. The initial comments from both of sides were positive and the prototype yielded recognition and enjoyment by all involved parties. The users were curious to find out about the recommended amount that was proposed to them and were very interested in reading the detailed descriptions on why the suggested amount was suited for their particular case. The employees appreciated the ease of use the prototype provided for generating life insurance quotes for customers and the detailed descriptions of why the particular life insurance amount was recommended to them.

Here are some additional key takeaways from the organization point of view:

- It was difficult to change the internal mind-set of the company. It took time and patience to get all the members of the organization on board with using the technology. 


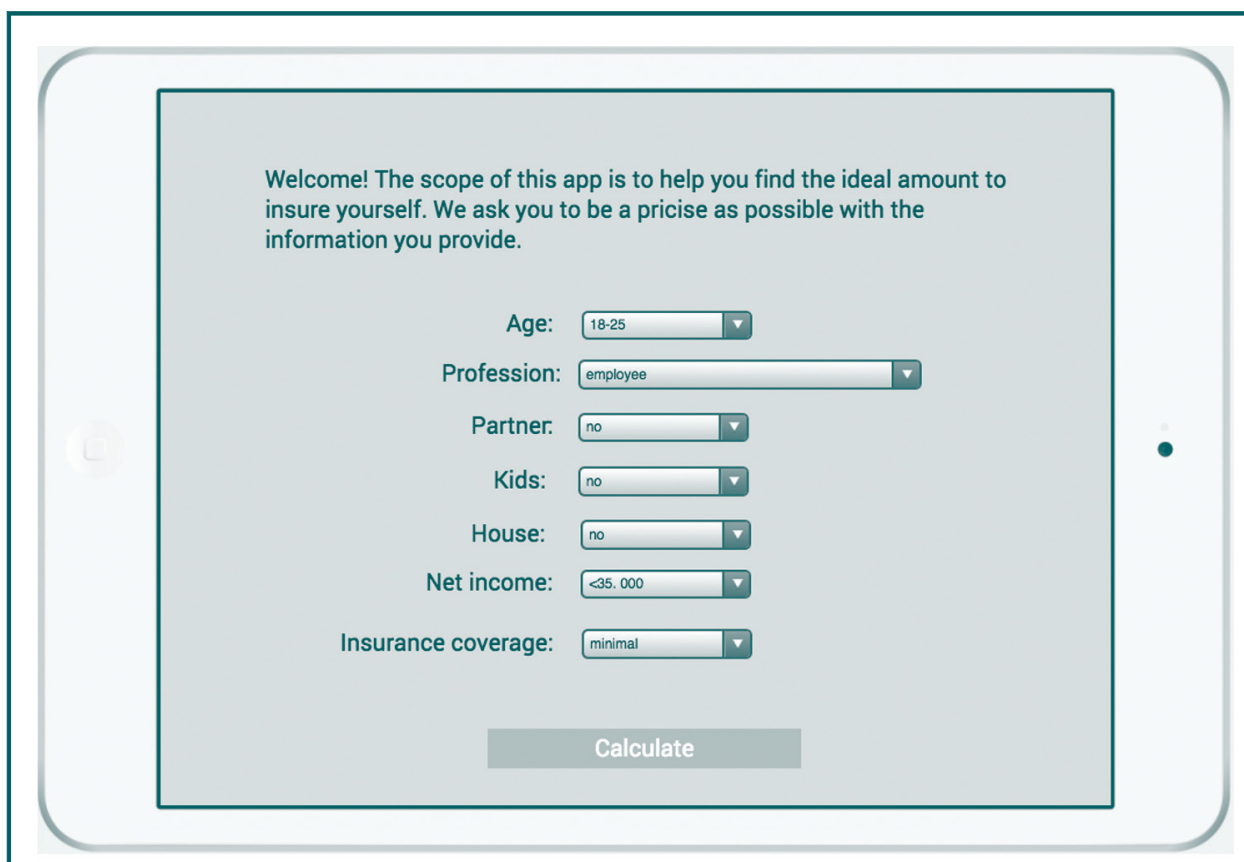

Notes: After the user clicks "Calculate", they are taken to the second screen (Figure 3) where the user is presented with the ideal amount of life insurance coverage as well as yearly fee they would need to pay to get that coverage. The last screen (Figure 4) shows additional detailed information on why the recommended amount is advisable for their particular case

- It was important to spread the knowledge and competency of the tool across the different key positions in the company and "energize" them about the solution. By having a shared language and communication daily, it allowed for a better understanding of the tool features.

- Including multiple stakeholders in the design phase of the prototype allowed employers and customers to bring the different features that are important to have so that the prototype is complete.

\section{Cyber risk and digital insurance policies}

The last area we investigated was the growing need for cyber security by businesses. As the pace of technological change continues unabated, organizations' reliance on technology has become critical to their ability to offer products and services. Technology is critical to help companies interact with customers and employees. The significant economic impact of cyber risks on companies as well as the recent attention of the media has led companies to look for solutions from available insurance products. Because of this and the increased frequency of cyberattacks, cyber risks are now widely accepted as one of the top emerging risks. Cyber insurance policies provide twofold benefits for the companies buying them: they create awareness that cyberattacks might happen and the company looks for options to reduce these risks. The act of buying cyber insurance makes the company put a price on the potential damage in case the company is compromised by a cyberattack. 


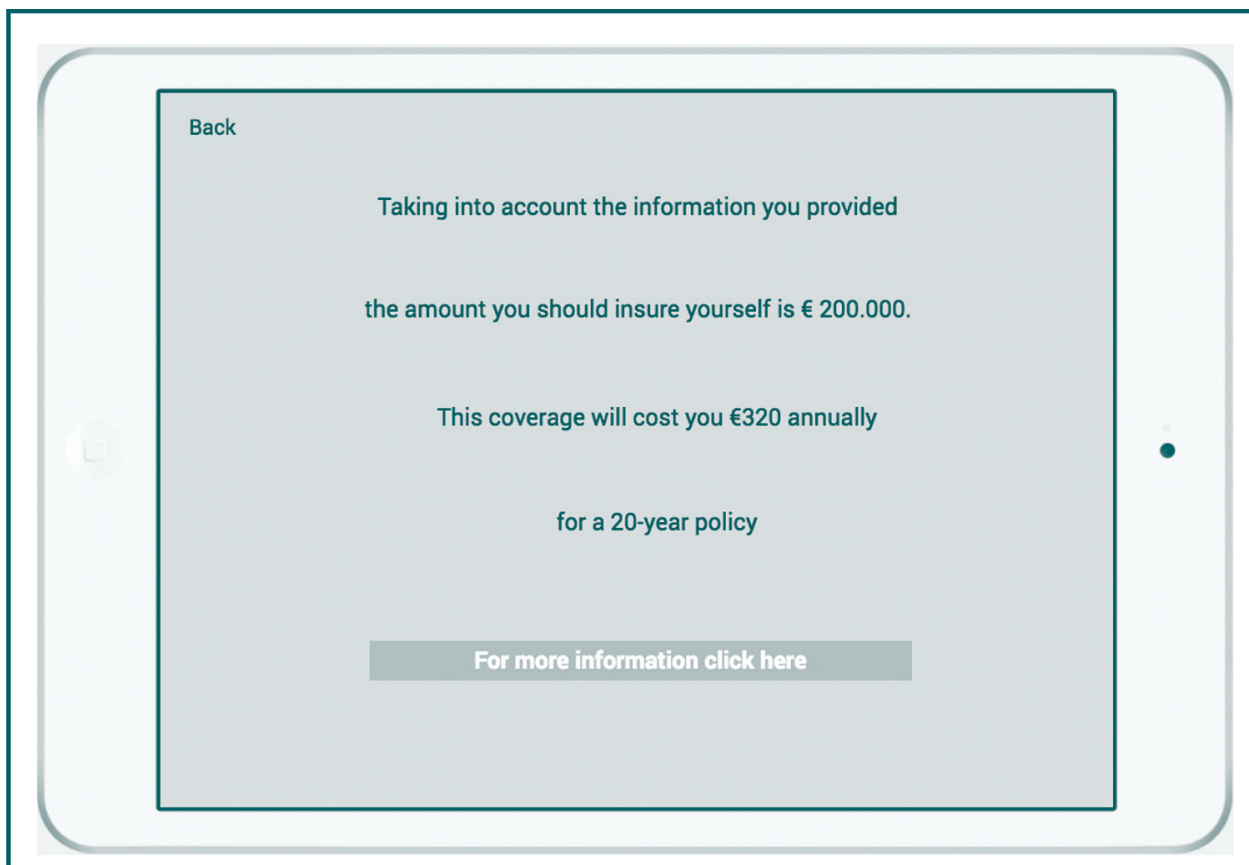

Note: Additionally, the screen shows links to further information on the coverage offered in case of death

To respond to the growing number of requests for insuring cyber risks by businesses, the company decided to enrich the portfolio of products it sells and offer insurance policies for cyber risks. The author studied insurance policies offered to businesses and several types of policies were found adequate. The following products were added to the portfolio:

- Liability risk - It provides compensation and legal support in the event of third-party claims, resulting from loss of personal and/or business data.

- Crisis costs - It provides compensation to undertake forensic investigations, reputation public repair, customer notification costs, IT services and cyber incidents.

- Fines - It provides compensation for research costs, legal assistance and administrative fines.

- Digital media breaches - It covers compensation and defense costs related to thirdparty claims against the client company arising out of multimedia activities (e.g. defamation, allegation or plagiarism).

- Cyber risk - It provides compensations for attacks from malicious software.

- Insurance policy for network interruption - It provides protection for loss of revenues or net profits associated with network downtime.

With these products, the company enriched its portfolio of insurance products covering cyber products. With these new products in the portfolio, the sales team started actively promoting these products to businesses. The initial results are positive, at the moment of writing of this paper, the SME has issued five cyber risk policies. 


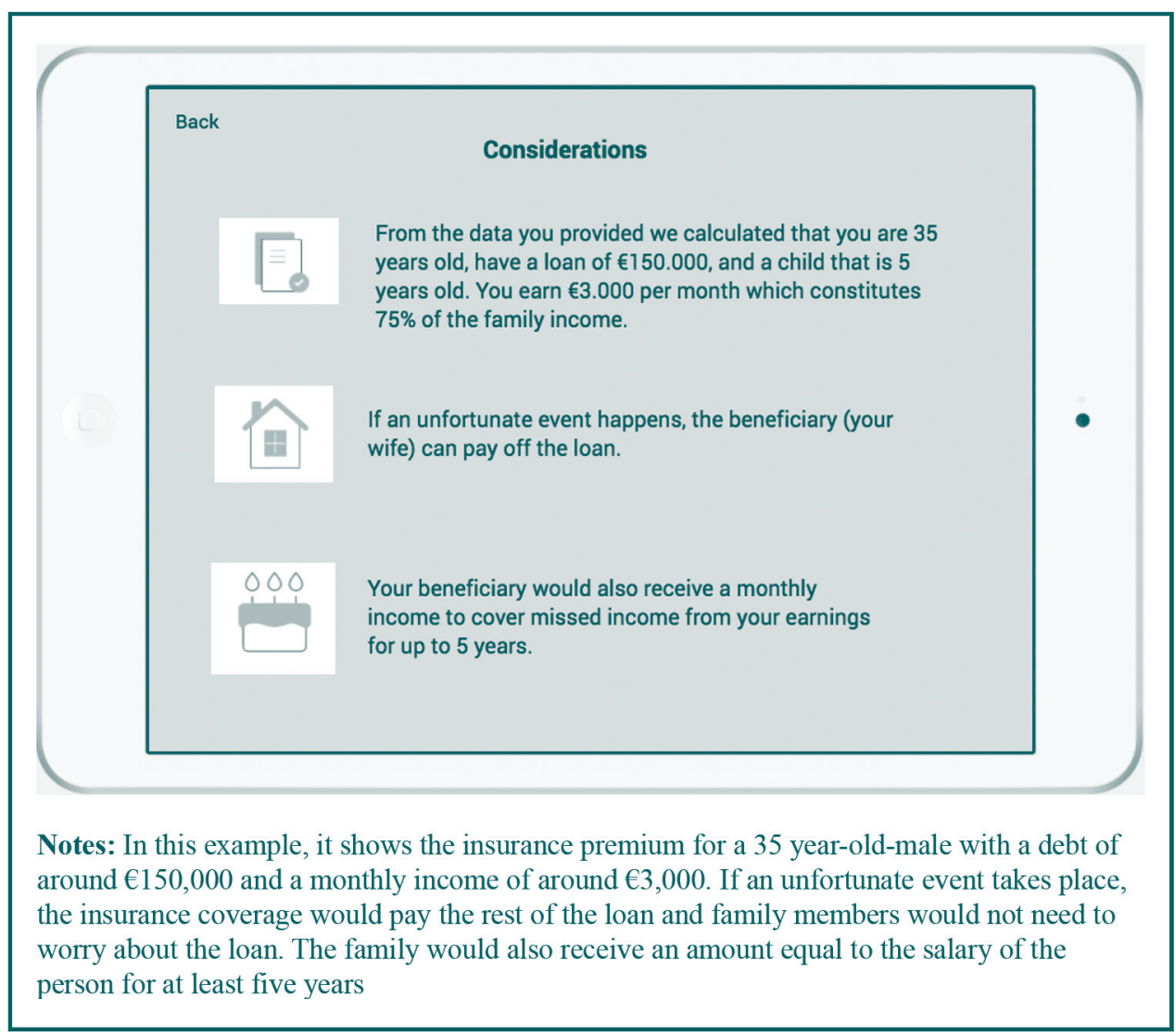

\section{Conclusions and future steps}

In this paper, we presented the steps a small Italian insurance company took to respond to the wave of digital transformation. The technology-based organizational transformation required the organization to be flexible and responsive to changes. The article describes how an organization can embrace digital innovation via internal innovation, buying from startups, partnering with startups or investing in startups. It also discusses how the company decided to respond to the challenge by partnering with Plug and Play, an accelerator connecting corporations to startups. The company found the first contacts promising when presented with a number of product possibilities.

The article shows how a company can apply for internal innovation and come up with a simple tool to bring insurers closer to their customers. The approach presented in this paper shows how different design-based approaches and tools can find ways to improvise in a rapidly changing environment, especially at a stage where the needs of users are uncertain. At the moment, the developed platform supports the needs of the company and their everyday work in the office. Future steps foresee full development of the prototype into a working application including the expansion and support of other types of insurance policies, especially car and home insurance policies. The idea will be passed on and developed further by a small separate company that already works on other solutions for insurance incumbents.

The company enriched the portfolio with new insurance products, tackling diverse digital risks. The company can offer insurance products to other companies that go through digital 
transformation and need to respond to cyber risk. The company has already started selling these products with positive results.

The management of insurance claims continues to be painful for customers - both retail and corporate. Well-managed claims can create a number of efficiencies for an insurance company and help with client retention. Yet at this moment, this area is still under-served by new technology. We see a great opportunity for driving change here and will be exploring startups offering solutions in this space.

The company can potentially increase retention rates by offering benefits for loyal customers or customers who have multiple insurance policies with the company. The company will look for a solution through digital channels to build a behavior-linked loyalty program that tracks people's activities and rewards them adequately. We plan to study reward mechanisms as a future extension of this work.

\section{References}

Brown, T. and Wyatt, J. (2010), "Design thinking for social innovation", Development Outreach, Vol. 12 No. 1, pp. 29-43.

Greineder, M., Riasanow, T., Böhm, M. and Krcmar, H. (2019), "The generic InsurTech ecosystem and its strategic implications for the digital transformation of insurance industry", 40th GI EMISA.

Kimbell, L. (2014), The Service Innovation Handbook: Action-Oriented Creative Thinking Toolkit for Service Organizations, BIS publishers.

Kohli, R. and Melville, N.P. (2019), "Digital innovation: a review and synthesis", Information Systems Journal, Vol. 29 No. 1, pp. 200-223.

Kumar, V. (2009), "A process for practicing design innovation", Journal of Business Strategy, Vol. 30 No. 2/3, pp. 91-100.

Nicoletti, B. (2017), "A business model for insurtech initiatives", The Future of FinTech, Palgrave Macmillan, Cham, pp. 211-249.

O'Brien, C. (2004), "Product innovation in financial services: a survey".

Van Boeijen, A. Daalhuizen, J. van der Schoor, R. and Zijlstra, J. (2014), "Delft design guide: design strategies and methods".

Wilson, J.D. Jr. (2017), Creating Strategic Value through Financial Technology, John Wiley \& Sons.

\section{Further reading}

Menhart, M., Pyka, A., Ebersberger, B. and Hanusch, H. (2004), "Product innovation and population dynamics in the German insurance market", Zeitschrift Für Die Gesamte Versicherungswissenschaft, Vol. 93 No. 3, pp. 477-519.

\section{Corresponding author}

Galena Pisoni can be contacted at: galena.pisoni@unitn.it
Keywords:

Digital transformation, Insurance, Product innovation, Entrepreneurship, Case study, Cyber risk

For instructions on how to order reprints of this article, please visit our website: www.emeraldgrouppublishing.com/licensing/reprints.htm

Or contact us for further details: permissions@emeraldinsight.com 